\title{
Diet and cancer: where are we and where are we going?
}

\author{
Gad Rennert \\ Department of Community Medicine and Epidemiology and CHS National Israeli Cancer Control Center, \\ Carmel Medical Center and Technion Faculty of Medicine, Haifa 34362, Israel
}

\begin{abstract}
Many studies have shown that overall dietary patterns, dietary components consumed, or mode of food preparation are all possibly relevant in either reducing or increasing the risk of cancer in animals or man. Yet, dietary intervention studies, stemming from laboratory and epidemiological observational studies have often failed to demonstrate the anticipated protection against cancer. One possible explanation for the discrepancy between the results of various observational and experimental chemo-prevention studies is the lack of control for biological diversity of the participants of these studies. It is suggested that future epidemiological studies provide evidence stratified by status of major metabolic polymorphisms pertinent to the study subject, and that future intervention studies take these differences into account in the design and analysis phases.
\end{abstract}

Cancer risk: Dietary intervention studies: Genetic susceptibility: Gene-diet interactions

An individual's probability of acquiring cancer is heavily influenced by dietary habits (Hill et al. 1994). Many studies have shown that overall dietary patterns, dietary components consumed or mode of food preparation are possibly all relevant in either reducing or increasing the risk of cancer in animals or man. Mechanisms of carcinogenicity or of protection thereof have been suggested in laboratory studies for a variety of dietary ingredients (Chlebowski \& Grosvenor, 1994). Yet, dietary intervention studies stemming from laboratory and epidemiological observational studies have often failed to demonstrate the anticipated protection against cancer (Albanes et al. 1996; Omenn et al. 1996; Alberts et al. 2000; Bonithon et al. 2000; Schatzkin et al. 2000). It is suggested that dietary intervention studies, or chemo-prevention trials, fail many times as a consequence of gaps in our knowledge about the specific mechanism of action of an intervened dietary component in an individual. Such an individual will be a carrier of a variety of genetic traits, which will define the reaction to, among other factors, biological components appearing in the diet. It is anticipated that no two individuals will react the same way to the same dietary exposure.

In their legendary report on the causes of cancer Doll \& Peto (1981) emphasise what is currently still the state-ofthe-art with regard to diet and cancer: various dietary components are definite contributors to the initiation and promotion of the carcinogenic process, while others are definitely protective against cancer formation. Yet, very little is known about the combined magnitude of cancer risk or protection conveyed by diet. The published estimate of $70 \%$ for cancer mortality attributed to diet shows the importance of this risk factor. The published CI around this point estimate $(10,70 \%)$ point to the instability of this estimate. Not much has changed in the precision of the estimation with regard to diet and cancer since this report was published $>20$ years ago.

A variety of agents have been studied in relation to cancer risk. Fruit and vegetables, their vitamins and pre-vitamins with antioxidant activity, fibres and other ingredients, as well as dietary fats, were the most studied. Some agents were found to be strongly protective from cancer while others were found to be strongly hazardous (Table 1).

\section{Dietary intervention studies}

Intervention studies in human subjects set out to test the cancer prevention ability of the protective agents. These studies employed mainly a variety of fibres and (pro-) vitamins such as $\beta$-carotene. Most of these well-designed studies have failed to show the anticipated protection (Rennert, 2002). Studies on fibre have not been successful in showing protection against colo-rectal cancer (Omenn et al. 1996; Alberts et al. 2000; Bonithon et al. 2000; Schatzkin et al. 2000) and studies on $\beta$-carotene could not demonstrate protection against lung cancer (Albanes et al. 1996; Omenn et al. 1996). The failure of intervention studies to replicate 
Table 1. Dietary factors studied in relation to cancer prevention ability

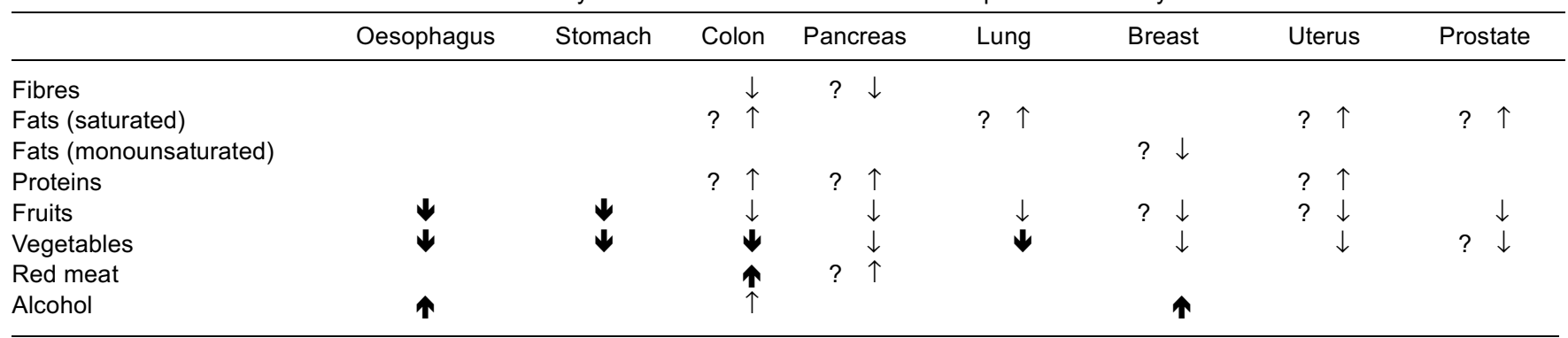

$\boldsymbol{\uparrow}$, increases risk; $\uparrow$, possibly increases risk; $\downarrow$, reduces risk; $\downarrow$, possibly reduces risk.

the predicted benefits of nutritional ingredients with regard to their cancer prevention potential could be explained in many ways. Wrong choice of intervention products, wrong study regimens with regard to timing of intervention in life cycle, intervention dosage, length of intervention and of follow-up and wrong choice of intermediate end points or markers could all be implicated as being responsible for the failure. Yet, it is possible that this generalized study failure is due to a more fundamental paradigm error such as ignoring the role of individual and group variation, reflected by differences in prevalent genetic polymorphism traits such as those encoding for phase I and phase II enzymes (Patterson et al. 1999).

\section{Genetic susceptibility}

While familial background and specific mutations in tumour suppressor genes or in oncogenes are established risk factors for a variety cancers, these specific mutations are relatively rare and account for only a relatively small proportion of all cancer cases. Other, often very common, polymorphisms in genes encoding for metabolic enzymes can be of much greater importance to the overall probability of cancer in a large population. These metabolic enzymes include mainly the phase I and phase II enzyme systems, as well as genes encoding electrophile scavenging, and DNA repair mechanisms. All these systems are mechanisms for reducing the harmful effects of environmental carcinogens, including carcinogenic processes initiated by dietary habits. Many other enzyme systems relevant to cancer risk, such as those controlling the hormonal pathways, are also controlled by genes that are polymorphic in man. Metabolic enzyme activity and response to carcinogens are dependent on the structure of the gene that encodes them, but can also often be modified by diet as well as by other behaviours, such as smoking.

\section{Genetic susceptibility}

It is not uncommon to find considerable disagreement in the results of epidemiological studies of a specific dietary component and the risk of a specific cancer. Much effort has been put into trying to explain such differences by means of demographic and geographic variation. Much less effort, however, has been invested in understanding the differences in studies and study results due to variation in distribution of polymorphic genes between the studied populations. It is logical to expect interaction between consumption levels of a specific dietary component and the polymorphic gene status, to determine whether or not this food item will contribute to the formation of cancer in a given individual or population. For example, Lin et al. (1998) showed that the protective effect of isothiocyanate in cruciferous vegetables on the risk of colo-rectal cancer is highly dependent on glutathione transferase M1 polymorphic status. Ma et al. (1999) showed methenyltetrahydrofolate reductase status to strongly influence the relationship between folate consumption and colo-rectal cancer risk and Chen et al. (1998) showed that red meat consumption is hazardous (with regard to colo-rectal cancer) only to $\mathrm{N}$-acetyl transferase 2 (NAT2) fast metabolizers.

Intermediate analyses of the relationship between the consumption of fruits, vegetables and fibre and the risk of developing colo-rectal cancer, stratified by polymorphisms of the NAT2 gene, were carried out using the Molecular Epidemiology of Colorectal Cancer (MECC) study database. The MECC study is a population-based study of all invasive colo-rectal cancers diagnosed in northern Israel since 1998. Population-based, age, gender and religion controls were matched to incident cancer cases. All study participants underwent an extensive interview, including, among other items, a validated semi-quantitative foodfrequency questionnaire and donated venous blood. Daily consumption levels of fruits (no. of portions), vegetables (no. of portions) with specific attention to cruciferous vegetables and fibres $(\mathrm{g} / \mathrm{d})$ were calculated. NAT2 status was determined in the DNA extracted from venous blood. Included in this interim analysis were 1200 colo-rectal cancer patients and 1300 controls. Analyses were univariate, but were stratified on gender, age and gene status. Consumption by portions was divided into quartiles according to the distribution of the variable in the total population of the controls. The cut-off point for fibre consumption was set at $15 \mathrm{~g}$, a level corresponding to the separation between the first three quartiles and the fourth quartile. Odds ratios (OR) were calculated, comparing consumption of the fourth quartile with that of the first quartile.

Vegetables, but not fruits, were found to have a protective effect against the development of colo-rectal cancer in the study population. The protective effect of vegetable consumption was statistically significant (OR 0.52, $95 \% \mathrm{CI}$ $0.37,0.74 ; P<0.05$; Fig. 1) while the effect of fruits was non-significant (OR 1.18, $95 \%$ CI 0.84, 1.67; Fig. 2). 


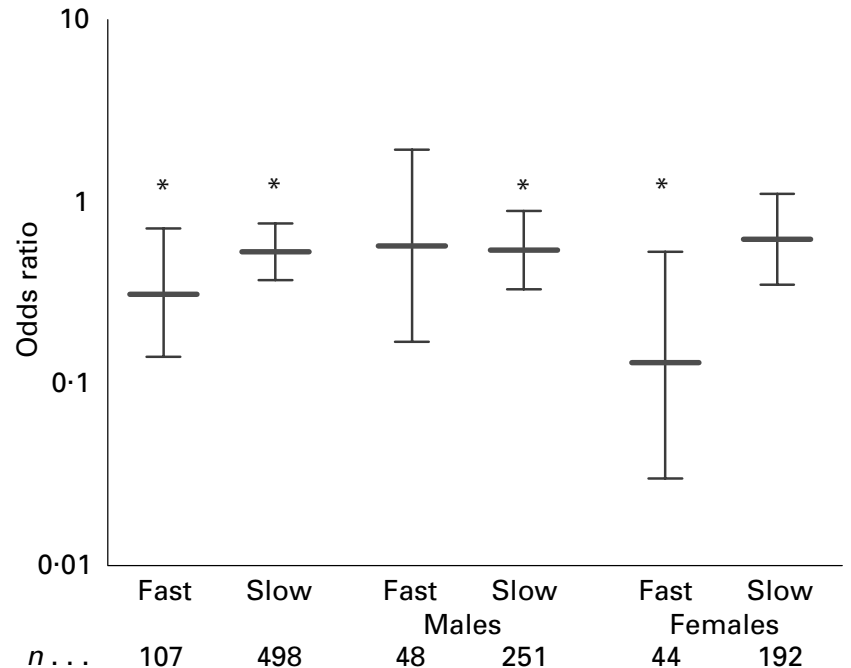

Fig. 1. Vegetable consumption and risk of colo-rectal cancer by $\mathrm{N}$-acetyltransferase 2 gene status using data from the MECC Study database (for details, see p. 60). A comparison of 4th $v$. 1st quartiles of consumption (portions). Values are odds ratios with $95 \%$ confidence intervals represented by vertical bars. ${ }^{*} P<0.05$.

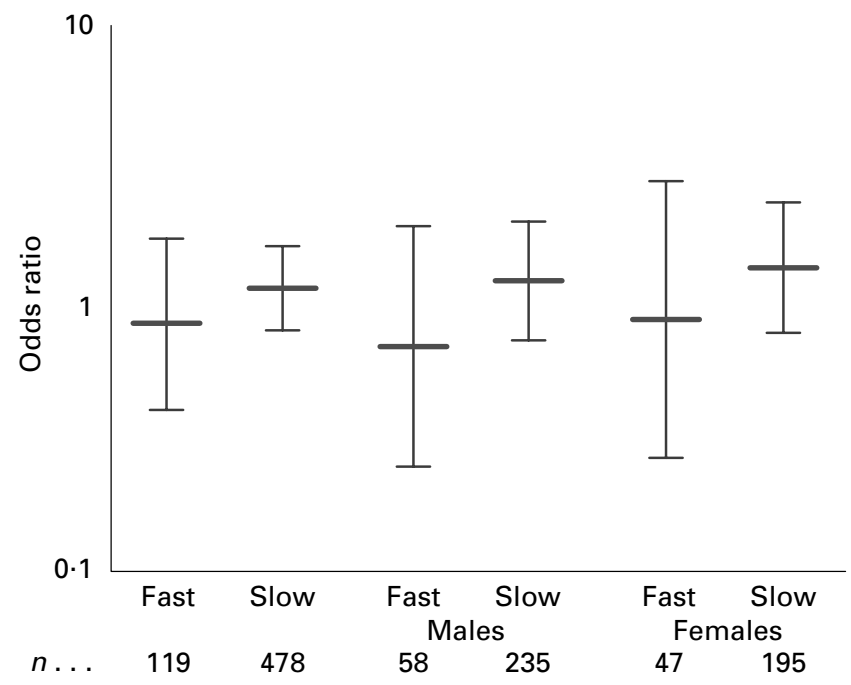

Fig. 2. Fruit consumption and risk of colo-rectal cancer by $\mathrm{N}$-acetyltransferase 2 gene status using data from the MECC Study database (for details, see p. 60). A comparison of 4 th $v$. 1st quartiles of consumption (portions). Values are odds ratios with $95 \%$ confidence intervals represented by vertical bars.

Consumption of cruciferous vegetables had a marginally significant protective effect (OR 0.79, $95 \%$ CI 0.57, 1.09; $P<0 \cdot 05$; Fig. 3). Fibres were not shown to carry a protective effect (OR 1.00, $95 \%$ CI 0.77, 1.31; Fig. 4).

Major differences were noticed between males and females in the risk or protection function of these dietary items. Stratifying the results by the NAT2 status led to significant differences in the results of this analysis. Women who were found to be fast metabolizers of NAT2 experienced a much stronger protective effect of vegetable consumption (OR $0 \cdot 13,95 \%$ CI $0 \cdot 03,0 \cdot 53$ ) than did women who were slow metabolizers or null type (OR 0.62, $95 \%$ CI $0 \cdot 35,1 \cdot 1$; Fig. 1$)$.

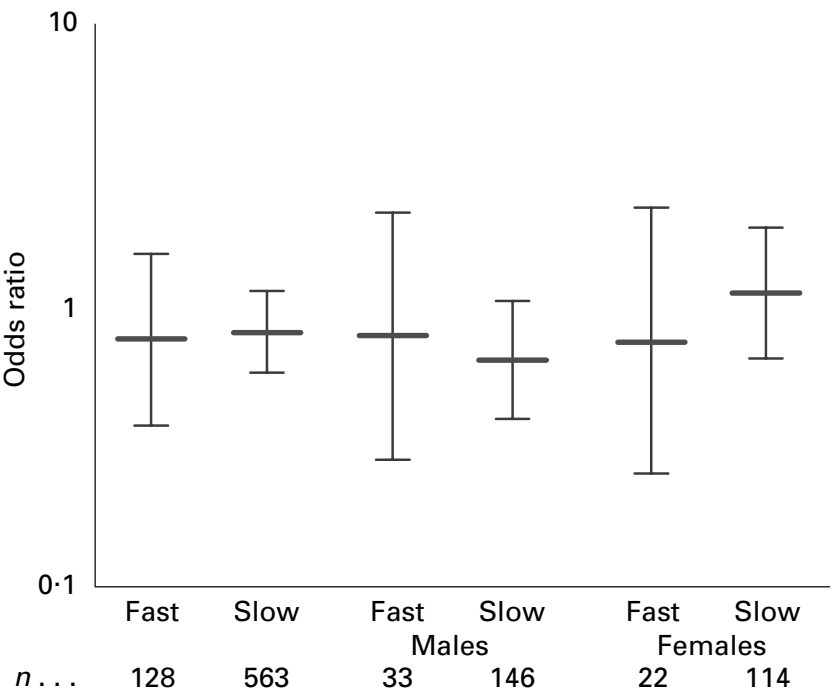

Fig. 3. Cruciferous vegetable consumption and risk of colo-rectal cancer by $\mathrm{N}$-acetyltransferase 2 gene status using data from the MECC Study database (for details, see p. 60). A comparison of 4th $v$. 1st quartiles of consumption (portions). Values are odds ratios with $95 \%$ confidence intervals represented by vertical bars.

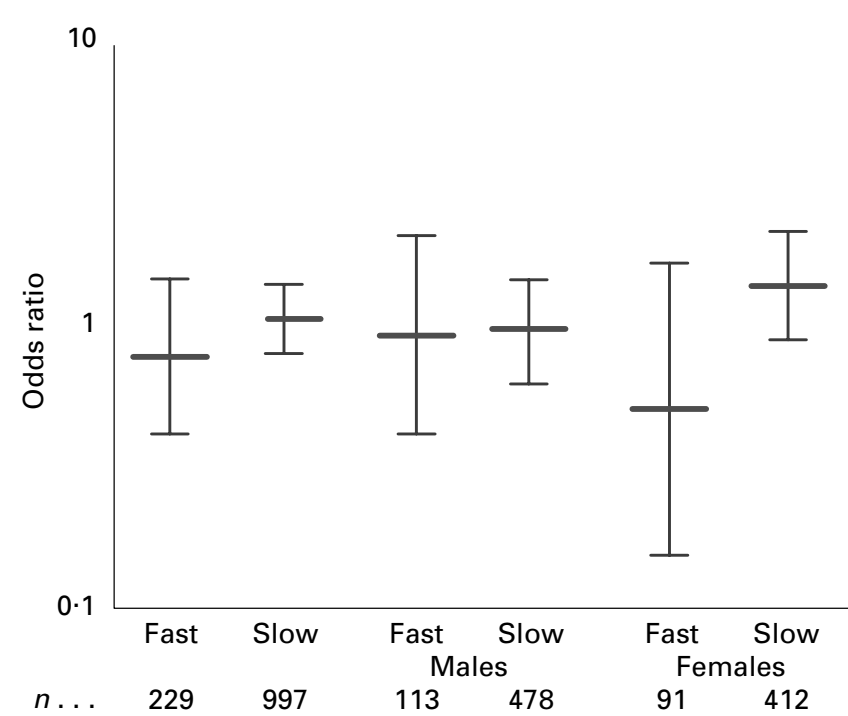

Fig. 4. Fibre consumption and risk of colo-rectal cancer by $\mathrm{N}$-acetyltransferase 2 gene status using data from the MECC Study database (for details, see p. 60). A comparison of $15 \mathrm{~g} / \mathrm{d} v$. $>15 \mathrm{~g} / \mathrm{d}$. Values are odds ratios with $95 \%$ confidence intervals represented by vertical bars.

\section{Summary}

It is possible that many of the differences in the results of earlier nutritional epidemiology studies could be made smaller if the data were corrected for certain polymorphisms. Failing to do so can lead to the formation of wrong hypotheses and hence the development of wrong interventions. Alternatively, polymorphic traits of participants of intervention studies could have been taken into account at the analysis stage, assuming that consideration was given to individual genetic typing and that relevant measurements were taken. 
It is suggested that future epidemiological studies provide evidence stratified by status of major metabolic polymorphisms pertinent to the study subject, and that future intervention studies take these differences into account in the design and analysis phases.

\section{References}

Albanes D, Heinonen OP, Taylor PR, Virtamo J, Edwards BK, Rautalahti M, Hartman AM, Palmgren J, Freedman LS, Haapakoski J, Barrett MJ, Pietinen P, Malila N, Tala E, Liippo K, Salomaa ER, Tangrea JA, Teppo L, Askin FB, Taskinen E, Erozan Y, Greenwald P \& Huttunen JK (1996) Alpha-tocopherol and beta-carotene supplements and lung cancer incidence in the alpha-tocopherol, beta-carotene cancer prevention study: effects of base-line characteristics and study compliance. Journal of the National Cancer Institute 88, 1560-1570.

Alberts DS, Martinez ME, Roe DJ, Guillen-Rodriguez JM, Marshall JR, van Leeuwen JB, Reid ME, Ritenbaugh C, Vargas PA, Bhattacharyya AB, Earnest DL \& Sampliner RE (2000) Lack of effect of a high-fiber cereal supplement on the recurrence of colorectal adenomas. Phoenix Colon Cancer Prevention Physicians' Network. New England Journal of Medicine 342, 1156-1162.

Bonithon Kopp C, Kronborg O, Giacosa A, Rath U \& Faivre J (2000) Calcium and fibre supplementation in prevention of colorectal adenoma recurrence: a randomised intervention trial. European Cancer Prevention Organisation Study Group. Lancet 356, 1300-1306.

Chen J, Stampfer MJ, Hough HL, Garcia-Closas M, Willett WC, Hennekens CH, Kelsey KT \& Hunter DJ (1998) A prospective study of $\mathrm{N}$-acetyltransferase genotype, red meat intake, and risk of colorectal cancer. Cancer Research 58, 3307-11.
Chlebowski RT \& Grosvenor M (1994) The scope of nutrition intervention trials with cancer-related endpoints. Cancer 74, Suppl. 9, 2734-2738.

Doll R \& Peto R (1981) The causes of cancer: quantitative estimates of avoidable risks of cancer in the United States today. Journal of the National Cancer Institute 66, 1291-1308.

Hill MJ, Giacosa A \& Caygill CPJ (editors) (1994) Epidemiology of Diet and Cancer. Series in Food Science. New York: Ellis Horwood.

Lin HJ, Probst-Hensch NM, Louie AD, Kau IH, Witte JS, Ingles SA, Frankl HD, Lee ER \& Haile RW (1998) Glutathione transferase null genotype, broccoli, and lower prevalence of colorectal adenomas. Cancer Epidemiology, Biomarkers and Prevention 7, $647-652$.

Ma J, Stampfer MJ, Christensen B, Giovannucci E, Hunter DJ, Chen J, Willett WC, Selhub J, Hennekens CH, Gravel R \& Rozen RA (1999) Polymorphism of the methionine synthase gene: association with plasma folate, vitamin B12, homocyst(e)ine, and colorectal cancer risk. Cancer Epidemiology, Biomarkers and Prevention 8, 825-829.

Omenn GS, Goodman GE, Thornquist MD, Balmes J, Cullen MR, Glass A, Keogh JP, Meyskens Jr FL, Valanis B, Williams Jr JH et al. (1996) Risk factors for lung cancer and for intervention effects in CARET, the Beta-Carotene and Retinol Efficacy Trial. Journal of the National Cancer Institute 88, 1550-1559.

Patterson RE, Eaton DL \& Potter JD (1999) The genetic revolution: change and challenge for the dietetics profession. Journal of the American Dietetic Association 99, 1412-1420.

Rennert G (2002) Dietary intervention studies and cancer prevention. European Journal of Cancer Prevention 11, 419-425.

Schatzkin A, Lanza E, Corle D, Lance P, Iber F, Caan B, Shike M, Weissfeld J, Burt R, Cooper MR, Kikendall JW \& Cahill J (2000) Lack of effect of a low-fat, high-fiber diet on the recurrence of colorectal adenomas. Polyp Prevention Trial Study Group. New England Journal of Medicine 342, 1149-1155. 